\title{
Capturing Complex, Distributed Activities: Video-Based Interaction Analysis as a Component of Workplace Ethnography
}

\author{
K. Ruhleder \\ Library and Information Science \\ University of Illinois \\ Champaign, Illinois USA \\ E-mail: ruhleder@alexia.lis.uiuc.edu
}

B. Jordan

Institute for Research on Learning

Xerox Palo Alto Research Center

Palo Alto, California USA

E-mail: jordan@parc.xerox.com

\begin{abstract}
Organizations increasingly carry out their work by relying on complex, distributed activities supported by a wide range of technologies for synchronous and asynchronous communication and collaboration. How do we capture complex, distributed activities? What tools do we use in settings where even a team of trained ethnographers could not comprehend, much less record, all the interplays between team members, the subtleties of a look or tone, the shifts in orientation to people or objects in the workspace? In this paper, we explore the use of video-based Interaction Analysis to extend the ability of traditional ethnographic methods for data collection and analysis. We draw on a study of a distributed organization's use of remote meeting technologies to illustrate how this
\end{abstract}


approach contributes to the depth of insights to be garnered from workplace ethnography.

\section{INTRODUCTION}

Organizations increasingly find it necessary to engage in complex, distributed activities supported by a wide range of technologies for synchronous and asynchronous collaboration between geographically separated teams. These technologies include groupware, remote meeting technologies, and shared media spaces (c.f., Gaver 1992; Grudin 1994; Heath and Luff 1993). Developers and potential users of these technologies anticipate that they will profoundly alter the ways in which geographically distributed team members can work together. As a consequence, organizations are beginning to embrace them as a means for both fostering communication and managing the complexities inherent in distributed organizational forms (Hiltz and Turoff 1993, Sproull and Kiesler 1991, Ehrlich and Cash 1994).

Yet participation in electronic communities and work groups requires significant amounts of time and energy spent on learning the technology and integrating it into current organizational work practices (Bikson and Eveland 1990; Ruhleder, Jordan and Elmes 1996). The successful emergence and continued vitality of these virtual groups will depend on designers' abilities to understand complex work settings and to develop effective ways of supporting distributed work. The successful integration of these new technologies will also depend on the ability of organizational members to develop shared understandings of their applicability to local problems and new practices that incorporate these technologies (Eveland et al. 1994; Korpela 1994; Orlikowski and Gash 1994; Orlikowski 1993).

As researchers, what tools can we bring to bear on understanding the complex interactions between collaborative technologies and environments that span multiple physical locations and multiple organizational cultures? How do we analyze situations characterized by layers of activity, where multiple meanings are deeply embedded in each action and reaction? If we are to effectively contribute not only to the development and deployment of a new set of technologies, but to the establishment of a new paradigm of organization, we must continue to develop research methods and approaches that will allow us to gain a deep understanding of local work practices and the broader organization of work within a given enterprise.

We confronted these questions as we carried out a study of the headquarters of a distributed organization, The Holding Company (THC), which uses a variety of communication and information technologies to support work distributed across THC headquarters and ten business units. THC associates conduct the business of the organization through phone calls and face-to-face meetings, via electronic mail and shared databases, and with the support of remote meeting technologies including shared workspaces and video- and audio-conferencing. The members of THC head- 
quarters and business units are constantly challenged with integrating these technologies in ways that effectively support the needs of their distributed teams.

In the sections that follow, we briefly discuss the role of workplace ethnography in organizational analysis and technology development. We then outline the contribution that one specific technique, Video-Based Interaction Analysis, ${ }^{1}$ can make as a component of a broader ethnographic inquiry both as a technique for data collection and as the basis for in-depth multidisciplinary analysis. We describe how this technique contributes to conventional ethnographic analysis, and what new challenges and problems its use raises. In the final section, we draw on our field study to illustrate how this approach contributes to the depth of insights to be garnered from workplace ethnography (Ruhleder, Jordan and Elmes 1996).

\section{WORKPLACE ETHNOGRAPHY}

\subsection{Workplace Ethnography}

Ethnographic methods, originally developed by anthropologists as a means of studying exotic tribes (Malinowski 1922, 1979; Mead 1973, 1930), extend the methodological lenses typically used in IT research (Yates and Van Maanen 1996). ${ }^{2}$ These methods provide us with a means of studying our own subcultures, including communities, professions, experiences, and organizations (c.f. Becker et al. 1977; Gladwell 1996; Gregory 1983; Ruhleder 1994, 1995; Star 1995; Suchman 1987; Wolcott 1973), Workplace ethnography approaches organizational communities from a holistic perspective, focusing on both formal and informal systems; and on myth, narrative and identity as well as product and process. The insights gained from ethnographic work can often shed light on organizational problems. For instance, when time is characterized as a social construction (Dubinskas 1988), the temporal structures experienced by different occupational groups within a single organization can be identified as a source of conflict (Barley 1988), and a source of tension between managers and designers becomes clarified by juxtaposing managerial perspectives of product design as a clear-cut trajectory with the designers' more fluid, iterative

'We use the term "Interaction Analysis" (capitalized) to refer to the particular method of analysis we have been using, while "interaction analysis" (lower case) or "analysis of interaction" refers to the domain of interest. This domain, of course, is one that concerns a great many theoretical and practical persuasions, e.g., symbolic interactionism, phenomenology, social psychology, and a variety of schools of therapy.

${ }^{2}$ See Van Mannen (1988), Chapter 2, for a brief history of ethnography and different approaches to fieldwork. The book also includes examples from his own work on the police force. 
processes of shifting issues and representations (Bucciarelli 1994). Close study of work practices has uncovered the underlying mechanisms of local interpretation, integration, and adaptation of systems and artifacts (Gasser 1986; Markus 1994; Orlikowski and Gash 1994), and the resulting complexities of infrastructure (Star and Ruhleder 1996). Other ethnographic work has uncovered the social role representations and artifacts play, serving as boundary objects linking together multiple communities within and across organizations (Gerson and Star 1986).

With their central focus on the native/user, ethnographic workplace studies are increasingly becoming a source of insights not only for researchers but for organizational and technology designers as well (Beyer and Holtzblatt 1993; Blomberg et al. 1993; Ehn 1988; Jordan 1996b). Underlying much of this work is the view that learning and work take place within communities of practice (Lave and Wenger 1991), naturally occurring groups that arise more or less spontaneously around a particular task, technology or enterprise (Jordan 1996a). Within this perspective, the complexities of practice can best be understood by the thick description generated by a combination of observational and participatory methods (Darrah 1992; Brown and Duguid 1991; Holzblatt and Beyer 1995; Jordan 1996a; Orr 1986). In particular, these and other ethnographic techniques, including video analysis, can be used to understand and illustrate the complex ways in which collaborative activities are constructed and maintained, and the ways in which particular artifacts can support collaborative work (Dourish and Bellotti 1992; Heath and Luff 1991; Nardi et al. 1995; Suchman and Trigg 1991; c.f. also Button 1993; Greenbaum and Kyng 1991; Engestršm and Middleton 1993). Within CSCW, for instance, projects are often driven by extensive fieldwork that includes participant observation before the design phase and user participation during the design phase (Bentley, et al 1992; Hughes, Randall and Shapiro 1993; Shapiro, Tauber and Traunmüller 1996).

Ethnographic field work within organizational settings immerses the participant observer (the researcher) in the work practices and processes of the organization. Participant observers may sit in on meetings, talk formally or informally with various organizational members, obtain copies of documents, gather stories, watch events unfold, overhear comments (Lofland 1995). Questions arise in situ, just as the analytic framework arises out of the data itself, and field data may include interview transcriptions, field notes, meeting memoranda, sketches, even cartoons collected from cubicle walls. In some settings, the participant observer may be able to become a part of the organization by taking on some of the work, or by playing a legitimate role within the work setting. Including ethnographic techniques in the methodological repertoire when studying the workplace helps the researcher avoid, or at least guard against, several major pitfalls:

- they counteract the threat of irrelevance by focusing the study on naturally occurring work activities in real world settings;

- they guard against a "top-down bias," that is, a bias that privileges the views of managers and supervisors, by involving researchers in the daily life of workplace communities of practice; 
- they enable researchers to capture both what people say and what they in fact do, something not easily accomplished with interview studies.

All of these factors are crucial if we are to develop a robust understanding of work practices and contribute to effective and beneficial technical development and workplace redesign.

Recently, additional challenges have emerged in workplace research. Increasingly it has to be carried out in distributed settings where distributed actors carry out coordinated work activities through synchronous or often asynchronous interaction via various communication media, including email and groupware. In addition to requiring tools and methods for representing these work environments, their transformation must be mapped over time to track the changes that occur as new technologies become integrated into local work practices. We believe that ethnographic methodologies can help address these kinds of issues.

In our own ethnographic work, we draw on the tradition of anthropological fieldwork (Garfinkel 1984; Naroll and Cohen 1973) and the techniques of grounded theory to guide our data collection and analysis (Glaser and Strauss 1967; Strauss 1986). Interaction analysis, the specific technique we address in this paper, has been shaped primarily by conversation analysis and ethnomethodology, but is also rooted in ethnography, sociolinguistics, kinesics, proxemics, and ethology. In the next section, we discuss how video-based interaction analysis fits into ethnographic work. Video-based data are subject to a variety of limitations: the camera operator's notions of what is significant and what is not invariably influence the kind of record produced and video equipment is inherently more restricted in its information processing capacities than a human observer's sensory apparatus. However, we feel that videobased data and video-based analysis can complement and extend conventional methods of data gathering and that the use of video-based Interaction Analysis can form an integral part of ethnographic work.

\section{VIDEO-BASED INTERACTION ANALYSIS ${ }^{3}$}

\subsection{Doing Interaction Analysis}

Video-based Interaction Analysis (IA), as outlined by Jordan and Henderson (1995), consists of the in-depth microanalysis of how people interact with one another, their physical environment, and the documents, artifacts, and technologies in that environment. Like ethnography in general, IA looks for orderliness and patterns in people's routine interactions, but operates at a finer level of detail than conventional ethnographic observation. As stated earlier, the roots of this technique lie in ethnography, sociolinguistics, kinesics, proxemics, and ethology, but it has been shaped most

\footnotetext{
${ }^{3}$ In the sections that follow, we draw heavily on Jordan and Henderson (1995).
} 
consequentially by conversation analysis and ethnomethodology. The technique itself has emerged over the past twenty years as a distinct form of analysis. ${ }^{4}$ It is wellsuited to a wide variety of organizational settings in which people interact with a broad range of individuals and technologies. For instance, Jordan (1992) has used video data to explicate how authoritative knowledge is distributed in two highly technologized settings: an airline operations room, where knowledge is continually jointly produced, and a hospital setting, where it is vested in the technology and the physician.

Interaction Analysis involves several different types of activities on the part of the ethnographer or ethnographic team:

- Ethnographic context. Video taping is most productively done in conjunction with extensive ethnographic fieldwork. In the course of the fieldwork, specific interactions are identified for video taping. Participant observation, interviews, and the analysis of documents provide the contextual framework for selecting relevant interactions for video taping and furnish the background against which video analysis is carried out. In turn, the video data are analyzed as a component of the larger analytical effort. In studying THC, for instance, we learned about the importance of meetings between distributed teams. These collaborations are supported by remote meeting technologies, such as desktop conferencing, two-way video, and shared drawing spaces. The use of these technologies made it difficult for a single researcher to gather the salient data. As a consequence, we decided to videotape these kinds of interactions from both sides of the link.

- Entry: permission and set-up. Prior to the taping, the ethnographer must establish guidelines for confidentiality and obtain permission for video taping from the participants. The logistics of videotaping involve scoping out the setting, determining things like the optimal camera angles (see Figure 1) and how to change the tape unobtrusively, and making sure that the video equipment won't interfere with any other equipment used in the room during the course of the event or activity being taped.

- Content logging and transcripts. The next step is to create a content log of each tape containing summary listings of events. These logs provide an overview of the data corpus, and can be used for locating sequences for further analysis. Later on, they also serve as the basis for making transcripts of particularly interesting segments. Depending on the researchers' interests, transcripts may include both verbal and non-verbal interactions from the tape. Table 1 offers a sample of a content log, Table 2 offers a sample transcript of a meeting

${ }^{4}$ Jordan and Henderson describe the work of researchers in two of the laboratories associated with the development of Interaction Analysis, one at Michigan State University, which operated between 1975 and 1988, and one currently functioning as a joint venture between Xerox PARC and the Institute for Research on Learning (IRL). 


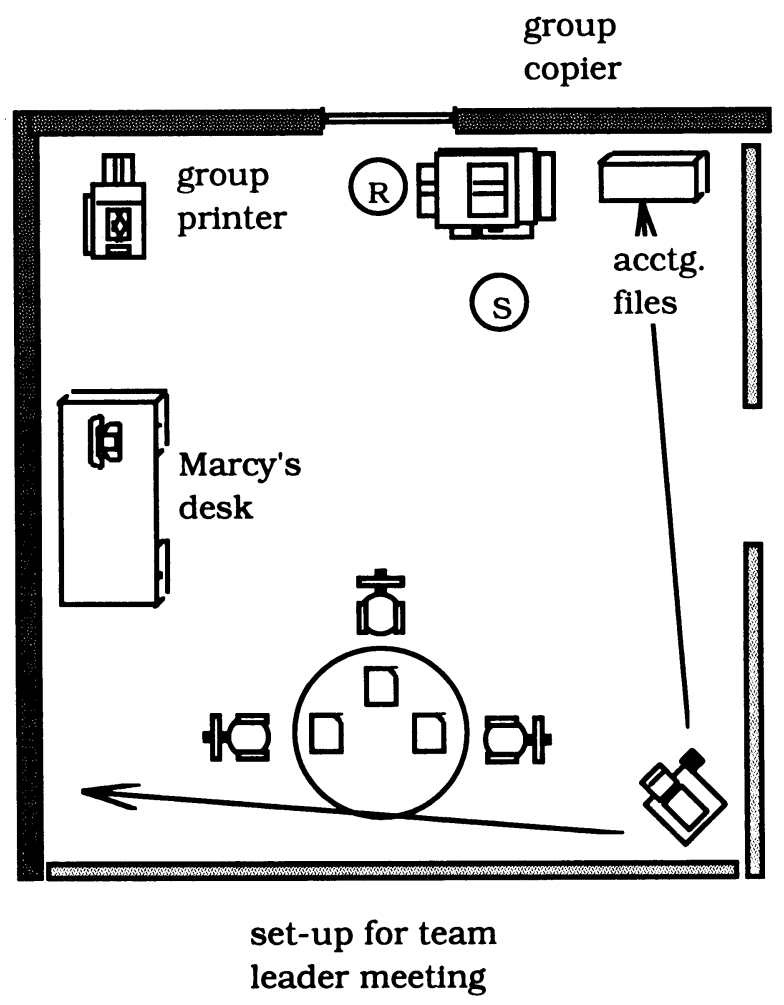

Figure 1 Sample Sketch with Camera Angle.

across two remote sites. An additional column can be inserted for notes, observations, links to other data, etc. ${ }^{5}$

- Collaborative tape analysis. A distinguishing feature of video-based IA is its reliance on multidisciplinary collaborative teamwork. Typically, a group of researchers convenes on a weekly basis for several hours of tape analysis where interesting sections of the tape are analyzed. Instead of using a preconceived coding scheme, analysts allow the categories to emerge out of a deepening understanding of the taped participants' interactions. In the course of multiple replayings, emerging patterns of interaction are checked against other sequences of tape and against other forms of ethnographic observations including field notes, interview transcripts, documentary materials, etc. Collaborative viewing

${ }^{5}$ Different researchers use different conventions for transcribing, usually determined by what depth of description is required for the type of analysis they are attempting to carry out. 


\section{Table 1 Sample Content Log.}

The following is an excerpt from a content log. It lists a counter, the participants, and the activity in which they are engaged. This is a very broad-grained look at the activities on the tape, and is used to flag sequences of potential interest. For instance, we can identify sequences of technical set-up and accidental breakdown.

\begin{tabular}{|c|c|c|c|}
\hline Counter & Participants & Activity & Notes \\
\hline \multirow[t]{2}{*}{$1: 23: 02$} & & tape begins & \\
\hline & D1 & $\begin{array}{l}\text { sets up computers for DTC; } \\
\text { speakerphone on }\end{array}$ & \\
\hline $1: 24: 40$ & A4 & announces that everyone is in & establish presence \\
\hline \multirow[t]{2}{*}{$1: 24: 53$} & D1 & accidentally hangs up phone & tech breakdown \\
\hline & & calls THC & \\
\hline $1: 25: 30$ & & speakerphone back on & \\
\hline $1: 25: 55$ & D1 & leaves to find D3 & \\
\hline \multicolumn{4}{|c|}{ more set-up; waiting omitted } \\
\hline \multirow[t]{2}{*}{$1: 27: 22$} & D1, D3 & enter room together & \\
\hline & D1 & $\begin{array}{l}\text { introduces everyone a and begins } \\
\text { meeting, explains agenda }\end{array}$ & $\begin{array}{l}\text { beginning of formal } \\
\text { meeting }\end{array}$ \\
\hline \multirow[t]{2}{*}{$1: 28: 00$} & D1 & $\begin{array}{l}\text { manipulates mouse and asks if } \\
\text { screen is coming through (as is) }\end{array}$ & \\
\hline & D1 & $\begin{array}{l}\text { gives introduction to presentation, } \\
\text { what screens will be shown during } \\
\text { DTC }\end{array}$ & \\
\hline \multirow[t]{2}{*}{ 1:29:06 } & D1 & $\begin{array}{l}\text { explains that D2 will be taking } \\
\text { over }\end{array}$ & \\
\hline & D1, D2 & switch chairs & $\begin{array}{l}\text { change in primary } \\
\text { speaker }\end{array}$ \\
\hline
\end{tabular}

helps neutralize the biases of the individual analyst while generating increasingly robust sets of analytic categories. Out of this collaborative analysis, the researchers construct an inventory of issues and hypotheses for further exploration.

Participants from the organization being studied are included in this collaborative viewing whenever possible so that they may contribute their insights. 


\section{Table 2 Sample Transcript.}

The following is an excerpt from a transcript. It outlines the verbal and non-verbal activities on one side of a meeting in which some participants are listening to the action via speakerphone (hence the glances at the speakerphone). The transcript is an emerging object, and may be further expanded if, for instance, certain non-verbals take on greater importance over time.

\begin{tabular}{|c|c|c|}
\hline Counter & Verbal & Nonverbal \\
\hline $1: 28: 13$ & $\begin{array}{l}\text { D1: I just want to do an introduction quick- } \\
\text { ly, OK, and then D2 will take it from this } \\
\text { point }\end{array}$ & $\begin{array}{l}\text { D1 looks at hisn otes } \\
\text { D1 looks at D2 } \\
\text { D1 looks at the screen } \\
\text { D1 looks back at his notes }\end{array}$ \\
\hline \multirow[t]{3}{*}{ 1:28:19 } & $\begin{array}{l}\text { D1: Basically what we talked about was, } \\
\text { was, the purpose of the system is to request } \\
\text { and get access to data from the Walker sys- } \\
\text { tem and }\end{array}$ & $\begin{array}{l}\text { D1 looks at his notes } \\
\text { D2 looks at D1 }\end{array}$ \\
\hline & $\begin{array}{l}\text { D1: we've talked about data and how we're } \\
\text { going to label it and those things and }\end{array}$ & $\begin{array}{l}\text { D1 looks at his notes } \\
\text { D1 makes a listing or outlining gesture } \\
\text { with his hand on the table. }\end{array}$ \\
\hline & $\begin{array}{l}\text { D1: basically what this system, this is the } \\
\text { mechanism to request the information }\end{array}$ & $\begin{array}{l}\text { D1 reaches over to the mouse on } \\
\text { "basically" } \\
\text { D2 watches the screen }\end{array}$ \\
\hline \multirow[t]{3}{*}{ 1:28:42 } & $\begin{array}{l}\text { D1: We have something, a box up here } \\
\text { called "project" and it's really no more than a } \\
\text { way of tagging the requests, or grouping the } \\
\text { requests a certain way. And what we're go- } \\
\text { ing to walk through is an example }\end{array}$ & $\begin{array}{l}\text { D1 gestures briefly at the screen (to the } \\
\text { box called "project") } \\
\text { D1 looks at the speakerphone }\end{array}$ \\
\hline & $\begin{array}{l}\text { D1: of use, um, the quarterly balance sheet } \\
\text { process as an example of walking through } \\
\text { these screens. }\end{array}$ & $\begin{array}{l}\text { D1 looks around } \\
\text { D1 makes "presentation" gestures with his } \\
\text { hands (as in, here is something for you) } \\
\text { D1 looks back at the screen }\end{array}$ \\
\hline & $\begin{array}{l}\text { D1: So, I think I'll just let D2 take it, show } \\
\text { you how it works, and get your feedback on } \\
\text { this. }\end{array}$ & $\begin{array}{l}\text { D1 and D2 trade places as he talks } \\
\text { D2 moves to the computer and puts his } \\
\text { hand on the mouse } \\
\text { D1 picks up a folder from a table against } \\
\text { the wall }\end{array}$ \\
\hline 1:29:11 & & $\begin{array}{l}\text { D2 sits down } \\
\text { D1 picks up his folder from a side table }\end{array}$ \\
\hline 1:29:13 & & D1 sits down \\
\hline 1:29:15 & $\begin{array}{l}\text { D2: OK, right off the bat as D1 mentioned } \\
\text { we wanted to try to put together an applica- } \\
\text { tion here that would hit on intuitiveness, I } \\
\text { guess, to try to make it as easy as possible to } \\
\text { get at the requests to the information that's } \\
\text { on the [mainframe] system }\end{array}$ & $\begin{array}{l}\text { D2 looks at screen } \\
\text { D1 looks at screen } \\
\text { D2 glances at notes } \\
\text { D2 looks down at hands } \\
\text { D1 looks down at hands } \\
\text { D2 glances back and forth between screen, } \\
\text { notes, and "nowhere" }\end{array}$ \\
\hline
\end{tabular}


Their contributions to the analysis help further elicit their view of the work world, forming an important counterpoint to the view of the ethnographic team and other researchers. Ideally, this joint analysis also provides a mechanism for feedback into the organization studied and might also lead to the construction of a "jointly told tale" (Van Maanen 1988:136ff) bringing together the voice of the ethnographer and the informant.

These activities are iterative and frequently overlap. Content logs generate potential tape sequences for analysis; tape analysis suggests further content logging and transcribing with emergent categories in mind. This, in turn, identifies new sequences for analysis, or suggests new venues for video taping.

\subsection{Advantages of Video-Based Interaction Analysis}

Under appropriate circumstances, video-based IA can form a powerful component of ethnographic workplace analysis for a variety of reasons:

- IA creates a permanent data corpus. Video data provides a rich ${ }^{6}$ and relatively permanent primary record available for an unlimited number of viewings and listenings. Individuals and groups of researchers can return to the video record over time as questions change and hypotheses develop.

- IA provides access to behavior invisible without replay technology. Many of the phenomena of interest to us in workplace analysis emerge only on repeated viewing. In addition, a videotape can be played in slow or accelerated motion, thereby exposing otherwise invisible patterns in the movements of persons or artifacts. In a distributed setting, simultaneous video taping of events at multiple sites makes possible coordinating remote events for purposes of analysis. It allows us to understand what happens at site B contemporaneous with or following events at site $\mathrm{A}$.

- IA captures complex data. Even for a trained observer, it is simply impossible to keep track of the overlapping activities of several persons with any accuracy or any hope of catching adequate detail. In multioperator workplaces, ethnographers are forever frustrated by the necessity to decide on whom to focus. Video is particularly useful in settings characterized by dense, concurrent

${ }^{6} \mathrm{We}$ draw on Daft and Lengel (1986, p. 560) for our definition of media richness, believing that video-based data provides "multiple cues via body language and tone of voice, and message content...expressed in natural language." This contrasts with Lee's (1994) definition of the richness as "an emergent property on the interaction between the communication medium and its organizational context." From this perspective, the video tape itself can be rich or lean, depending on who works with it and how. For this reason, we strive for the richness of multiperson, multidisciplinary analysis. 
dialogues and behaviors. It provides a level of detail that is unattainable for methods that rely on note taking or on-the-spot observational coding, allowing the analyst to later "pick apart" the complex interactions taking place.

- IA counteracts certain forms of recorder bias. Observers and interviewers invariably highlight important aspects and pass over what they consider to be at the time unimportant aspects of the activities they observe. The camera, on the other hand, records events as they happen, with consistent and known bias stemming from equipment characteristics such as available camera angle, audio recording levels, and the like.

- IA counteracts bias of the individual analyst. Multidisciplinary group analysis is particularly powerful for neutralizing preconceived notions on the part of individual researchers. It provides a critical corrective to the tendency to see in the interaction what one is conditioned to see or even wants to see. This is especially apparent when members of the organization being studied are included in these sessions.

- IA avoids the say/do problem. What people say they do and what they do in fact are not necessarily the same, which is why anthropological ethnography involves both asking questions and observing interactions. Field notes and other data can identify some discrepancies. Video recordings approximate the characteristics of direct observation of an event, thus providing optimal data on what really happened rather than particular accounts of what happened, such as people's recollections and opinions.

- IA provides access to members' categories and world view. Given that analysts have strong preconceived notions of what the world is like, it is often difficult to see when they differ from those of workplace participants. For example, we identified several sequences in which the accountants' questions weren't being fully answered by the developers, which we hypothesized might be explained by the imbalance in IS-user power relationships (c.f. Markus and BjørnAndersen 1987). In viewing these sequences, an alternate explanation emerged that suggested, instead, that the problem stemmed from different understandings of the role the application would play, rooted in different practices.

- IA exposes mechanisms and antecedents. Video provides process data rather than snapshot data. Since video records the phenomenon of interest in context, it is possible to ask about antecedents, varieties of solutions produced on different occasions, and questions of what led up to any particular state. While problems or breakdowns are often fairly obvious in workplace analysis, their antecedents may not be easily apparent. Video can help researchers and (where this is an option) participants look at and evaluate antecedents, potentially figuring out how to mitigate against particular chains of events. 


\subsection{Problems in Capturing and Analyzing Video-Based Data}

Video-based Interaction Analysis, however, is not without its own problems and costs. A variety of issues have arisen for us and other analysts in the course of this kind of work:

- Individuals are concerned about confidentiality. In most settings, the people being videotaped are concerned about confidentiality: who will see the tapes, and will my performance be judged by my supervisor? Clarifying who will have access and the right of individuals to review and potentially erase any tape sequence forms an important part of the "up front" work the ethnographer must do. Our policy is that supervisors are not allowed to see video tapes of their subordinates unless explicit permission is granted and that anyone may request that any segment in which they appear be erased.

- Companies are concerned about confidentiality. In working in corporate environments, senior management may be concerned about the extent of researchers' access to sensitive information, and may not permit audio and video recordings in particular settings. Access needs to be clarified up-front and may be renegotiated over time. This may require going up the formal chain of command for authorization (Nardi et al. 1995).

- Video-based Interaction Analysis is time consuming and expensive. This point cannot be overstated. Beyond the cost of the equipment, this form of data collection and analysis requires substantial investment in trained personnel. The work of taping necessitates that someone intelligently set up and monitor the camera, as well as record supplementary field notes and collect relevant documentary materials. Similarly, the analysis ideally involves the on-going participation of a multidisciplinary team of analysts. The cost of all this can quickly become prohibitive.

- Video-based data is difficult to work with. A variety of annotation and analysis programs have been developed, including MacSHAPA® (Sanderson et al. 1994) and VideoNoter (Roschelle and Goldman 1991), but no standards have emerged thus far and each has its limitations. Even with these tools, video records are clumsy to access, annotate, and integrate with other materials such as observer notes, key stroke data, or physiological or state measurements. However, emerging annotation and synchronization technologies promise to make this type of analysis easier in the future.

- Incorporating screen-capture ups the ante on time, expertise and complexity. Synchronous screen capture in settings where computing technologies or video monitors form a component of the interaction at hand suffer from all of the problems discussed above in terms of cost and necessary expertise. In addition, the elaborate technologies required for screen capture further complicate the problems of working with multiple streams of data.

- Camera effects may arise. The degree to which people are influenced by the presence of a camera is an empirical question that cannot be decided in principle 
but must be investigated on each occasion of camera work. Evidence that the camera mattered to participants can sometimes be found on the tape itself in the form of visible monitoring of, or remarks about, the camera, particularly when there is some kind of breakdown or deviation from routine. Our experience shows, however, that people quickly habituate to the camera as they become engaged in their own work tasks, especially if there is no operator behind the camera. $^{7}$

We may never be able to fully overcome some of these difficulties, and others will have to be addressed anew in each setting. Many of them, for example, confidentiality issues, arise in some form or other in all ethnographic work, whether or not videotapes form a part of the data corpus. Despite these difficulties, however, we believe that including the capture and analysis of video-based data as a component of ethnographic work is worth the effort for all of the reasons outlined in previous sections. It has helped us to understand the complex work environment at THC and, in particular, the ways its members rely on remote collaborative technologies to conduct their work over multiple distributed sites. In the following section, we provide examples of the analytic contributions of this technique.

\section{APPLYING IA TO REMOTE MEETINGS}

\subsection{Studying a Geographically Distributed Organization}

As mentioned above, we carried out an ethnographic study of The Holding Company (THC), which is using groupware and communication technologies to support a distributed work environment. THC headquarters manages ten business units distributed across the United States. LotusNotes $®$ and remote meeting technologies such as LiveBoard® and PictureTel® are widely disseminated in order to facilitate interactions between headquarters and these geographically distributed holdings. THC associates freely combine groupware and nongroupware technologies to create different possibilities for remote group work, depending on the circumstances, the local availability of specific technologies, and the preferences of group members.

We carried out fieldwork over a period of four months, during which we collected data through unstructured interviews, participant observation at THC headquarters and several business units, and review of on-line and paper materials. All thirty-two headquarters associates, most of the seven temporary staff, and some members of the business units were interviewed at least once over the course of the four months. The

${ }^{7}$ This may not be surprising in corporate settings, where participants are familiar with computers, video cameras, and tape recorders, but was also found to be the case in settings such as the huts of Mexican village women, where Jordan videotaped births conducted with the assistance of a midwife and family members (Jordan 1993). 
resulting dataset includes field notes, interview write-ups and partial transcripts, photographs, paper and electronic documents, and a set of video tapes capturing both sides of various small- and large-group remote interactions. Over the course of our field work, we were able to videotape four remote meetings, documented in a series of nineteen video tapes. We continue to develop and expand content logs, transcripts, and other documents relative to our analysis.

Our central concern in studying this organization has been the relationship between technology and everyday work practices, and the learning that has to take place in order to integrate technology and practices effectively and synergistically. Multiple factors, including local norms, physical infrastructures, and status differences influence who uses the remote meeting technologies, and to what purpose. Successful meetings require a great deal of preparatory work, including setting up, testing connections, and checking file formats when shared files are used. Teaching newcomers the mechanics of establishing a connection between two sites involves talking technically nonliterate individuals through an often ill-documented set of steps plagued by cryptic error messages. In addition to solving technical problems, remote meeting participants must figure out new ways of working together in settings with reduced context cues. We are interested in understanding how these issues interact with other aspects of organizational culture.

In our work, video-based IA has been extremely useful for pursuing hypotheses derived from other field data and for exploring a broad range of issues. These include issues of deep learning around technology, the interaction between competing paradigms in problem solving, and the distribution of authoritative knowledge across distributed workgroups. They also include the negotiation of local and global talk during the course of remote meetings, the ways in which particular technical arrangements shape participation frameworks, the role of infrastructure and local support staff in remote meeting facilitation and, finally, the ways in which distributed workgroups organize their interactions to exploit the positive affordances of remote meeting technologies and compensate for the negative ones.

Below, we draw on one particular example, the development of a relational database application to support the work of accountants at THC's headquarters, to illustrate some of the ways in which insights were generated by video analysis that most likely we would not have arrived at without this particular method.

\subsection{Designing an Application for Accountants}

One set of events we observed at THC was the interaction over time between two geographically distributed teams. A group of developers on the East Coast was designing a relational database application for accountants on the West Coast that would facilitate their access to information on a cumbersome legacy system. During ethnographic work, we observed two meetings between the teams, one face-to-face and one via PictureTel and LiveBoard, and recognized this as an opportunity for videotaping. We videotaped the following two meetings, one using PictureTel and 
West Coast - Accountants: A1 is the most senior, A2 next, and A3 the most junior of the three. A1 initiated the process. A4 is a member of the IS staff. She set up the computer and the camera, then left as the formal meeting began.

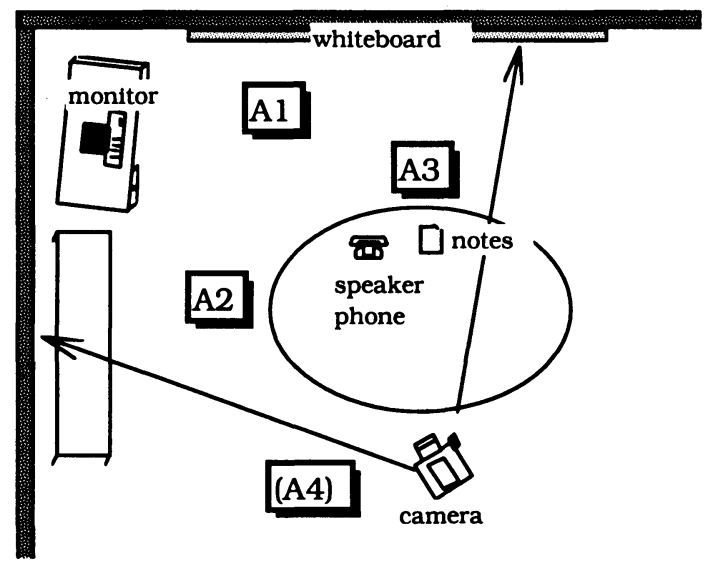

East Coast - Developers: D1 is the liaison with the accountants, D2 the project leader, and D3 a programmer. D4 is the ethnographer. She set up the room and the camera, and remained throughout the meeting.

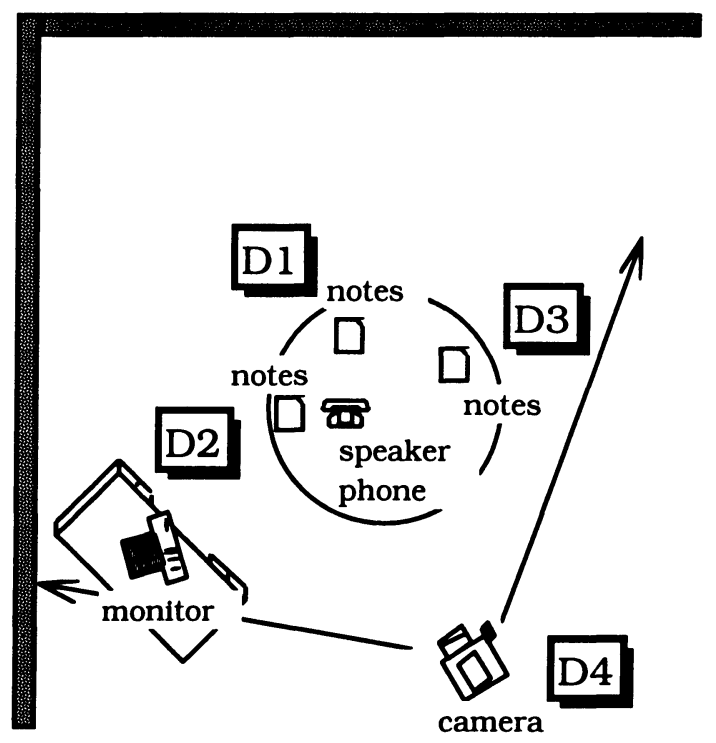

Figure 2 Sketches of the Two Meeting Sites. 
one using a DeskTop Conferencing (DTC) application allowing the two groups to view and manipulate the same application prototype on their respective monitors.

We use the process of the development of this application and the dialogue around the prototype demonstration activities to illustrate some of the ways in which video analysis can lead to crucial insights not available through other methods. In particular, we draw on the fourth meeting in the series, during which DTC and a speakerphone provided an audio link and shared screen. Analysis of the video data helped us more fully understand how the distributed set-up disturbed premeeting alignment activities, how the activities of other group members influenced asking and answering questions across the link, and how groups moved from and integrated local work and global work. Figure 2 presents sketches of the two sites.

\subsection{Disturbance in Premeeting Alignment Activities}

Premeeting activities are so much a part of an on-going practice that participants hardly ever think about what they consist. These activities include both lighthearted banter and serious asides, catching up on prior history, readying papers and props, and choosing places to sit. It is only in distributed meetings that taken-for-granted activities become apparent in their absence and unaccustomed activities are added. For instance, participants have to pay attention to setting up and maintaining the link even as they try to carry on both serious and lighthearted premeeting exchanges. Furthermore, where visual and to some extent auditory context clues are lacking, premeeting exchanges can become strained and burdensome. For example, a joke in face-to-face interaction unifies people in a joint activity (laughter) and focuses attention, thereby allowing a meeting to start with eyes and ears on the chairperson. This breaks down if the other side doesn't hear the joke, either due to limitations of the technology, or because the remote technologies precluded the teller from judging the appropriate point at which to insert the joke into the other side's on-going activities. Consider the following excerpt from a transcript of pre-meeting activities at THC (underlining indicates what the other side heard):

\begin{tabular}{|c|l|l|l|l|}
\hline & \multicolumn{2}{|c|}{ West Coast } & \multicolumn{2}{c|}{ East Coast } \\
\hline ctr. & \multicolumn{1}{|c|}{$\begin{array}{c}\text { accountants } \\
\text { nonverbal }\end{array}$} & \multicolumn{1}{|c|}{$\begin{array}{c}\text { accountants } \\
\text { verbal }\end{array}$} & \multicolumn{1}{c|}{$\begin{array}{c}\text { developers } \\
\text { verbal }\end{array}$} & \multicolumn{1}{c|}{$\begin{array}{c}\text { developers } \\
\text { nonverbal }\end{array}$} \\
\hline $1: 02: 08$ & $\begin{array}{l}\text { all turn to look at } \\
\text { A4, A3 goes toward } \\
\text { camera to where A4 } \\
\text { is standing }\end{array}$ & $\begin{array}{l}\text { A4: Hey, you guys, } \\
\text { can I show A3 here, } \\
\text { just at the end... }\end{array}$ & & \\
\hline & & & $\begin{array}{l}\text { D1: OK. is D3 here. } \\
\text { or }\end{array}$ & $\begin{array}{l}\text { D1 turns away from } \\
\text { table toward D2 }\end{array}$ \\
\hline & & & $\begin{array}{l}\text { D2: He's not here } \\
\text { yet }\end{array}$ & $\begin{array}{l}\text { D2 walks toward the } \\
\text { table }\end{array}$ \\
\hline
\end{tabular}




\begin{tabular}{|c|c|c|c|c|}
\hline 1:02:15 & & & $\begin{array}{l}\text { D1: Let me just } \\
\text { check on D3, if he's } \\
\text { not there. we'll start } \\
\text { the meeting, we'll } \\
\text { just get moving. }\end{array}$ & $\begin{array}{l}\text { D1 gestures first to- } \\
\text { ward the speaker- } \\
\text { phone, then to D2 } \\
\text { D1 leaves } \\
\text { D2 looks at the } \\
\text { screen, fiddles with } \\
\text { his watch }\end{array}$ \\
\hline 1:02:22 & $\begin{array}{l}\text { A2 starts looking for } \\
\text { his water bottle, } \\
\text { takes his notepad off } \\
\text { the table } \\
\text { A1 watches A4 and } \\
\text { A3 }\end{array}$ & $\begin{array}{l}\text { A4: Just take the } \\
\text { one that's on and } \\
\text { move it to off. I'll } \\
\text { check when I get } \\
\text { back. }\end{array}$ & & $\begin{array}{l}\text { D2 wanders out the } \\
\text { door, then back in } \\
\text { again }\end{array}$ \\
\hline 1:02:25 & A3 sits back down & $\begin{array}{l}\text { A3: I think I can } \\
\text { handle that }\end{array}$ & & $\begin{array}{l}\text { D2 wanders out the } \\
\text { door, then back }\end{array}$ \\
\hline 1:02:28 & $\begin{array}{l}\text { A2 tosses an empty } \\
\text { cassette tape onto the } \\
\text { table }\end{array}$ & $\begin{array}{l}\text { A4: That's what I } \\
\text { said yesterday }\end{array}$ & & \\
\hline 1:02:33 & $\begin{array}{l}\text { A1 looks at phone } \\
\text { A3 pulls phone } \\
\text { closer to group }\end{array}$ & $\begin{array}{l}\text { A1: } \underline{\mathrm{OK}} \\
\text { A3: We still con- } \\
\text { nected? }\end{array}$ & & \\
\hline & & & $\begin{array}{l}\text { D4: Can I hand you } \\
\text { this chair? }\end{array}$ & D2 moves a chair \\
\hline 1:02:36 & $\begin{array}{l}\text { A3 looks at A4 } \\
\text { A1 looks at the } \\
\text { phone }\end{array}$ & $\begin{array}{l}\text { A4: I think he was } \\
\text { going to get D4, D1 } \\
\text { was going to get D4. }\end{array}$ & & \\
\hline 1:02:39 & & A4: D1? & & \\
\hline 1:02:40 & $\begin{array}{l}\text { A3 leans toward the } \\
\text { phone, everyone } \\
\text { looks at the phone }\end{array}$ & $\begin{array}{l}\text { A3: Who's there? } \\
\text { Anyone there? }\end{array}$ & & \\
\hline \multicolumn{5}{|c|}{$\begin{array}{l}\text { (D4 clarifies who is on the East Coast. West Coast participants start to kid around, joking about } \\
\text { whether or not someone bought a fancy car.) }\end{array}$} \\
\hline 1:03:45 & & $\begin{array}{l}\text { A3: Well, we're } \\
\text { having a little dis- } \\
\text { agreement between } \\
\text { me and A1. }\end{array}$ & & $\begin{array}{l}\text { D1 walks in with D3 } \\
\text { All look very serious }\end{array}$ \\
\hline \multirow[t]{3}{*}{ 1:03:47 } & A2 grins at A4 & $\begin{array}{l}\text { A2: There's a } \\
\text { wager. }\end{array}$ & & \\
\hline & & $\begin{array}{l}\text { A1: Don't tell every- } \\
\text { one. }\end{array}$ & & \\
\hline & & $\begin{array}{l}\text { A2: Well. not really } \\
\text { a wager. }\end{array}$ & & \\
\hline
\end{tabular}




\begin{tabular}{|l|l|l|l|l|}
\hline 1:03:50 & $\begin{array}{l}\text { A1 glances over } \\
\text { briefly, turns back to } \\
\text { looking at the screen } \\
\text { A2 and A3 are grin- } \\
\text { ning }\end{array}$ & $\begin{array}{l}\text { A1: Don't talk about } \\
\text { it. }\end{array}$ & & $\begin{array}{l}\text { D1 sets down his } \\
\text { folder } \\
\text { D2 closes the door } \\
\text { D3 prepares to sit } \\
\text { down }\end{array}$ \\
\hline 1:03:54 & $\begin{array}{l}\text { A2 and A3 looking } \\
\text { at screen } \\
\text { A2 turns toward } \\
\text { speakerphone }\end{array}$ & & $\begin{array}{l}\text { D1: All right, we're } \\
\text { all set here. we got } \\
\text { D3. D2 and myself. }\end{array}$ & $\begin{array}{l}\text { D1 starts to sit down } \\
\text { D2 sits down }\end{array}$ \\
\hline
\end{tabular}

On the accountants' side, A4 is busy showing A3 something (1:02:08)while A2 looks for a water bottle and A1 watches A4 and A3 (1:02:22). After they are done with that aspect of the set-up, A1 checks in with the other side with an "OK?" When there is no response, A3 asks if they are still connected or if the link has been broken (they haven't heard anything from the developers for a little over fifteen seconds). A4 then answers, "I think he [D1] was going to get D4" (1:02:36), making a wrong inference about the currently available participants. D4 and D2, meanwhile, are busy with their own concerns of rearranging the physical space for the meeting. They miss A1's "OK?" as well as A4's inaccurate inference about getting D4 and A4's query, "D1?" (1:02:39). It isn't until A3 makes a special effort to attract their attention and clarify availability ("Who's there? Anyone there?" 1:02:40) that the designers finally respond, after which premeeting activities can continue on both sides.

In the end, the formal part of the meeting begins abruptly. When D1 walks in with D3 (1:03:45), the designers are ready for the transition to the formal meeting while the accountants are still in the informal phase. D1 walks to the table, sits down, and begins at 1:03:54: "All right, we're all set here, we got D3, D2 and myself." What D1 cannot see is that the accountants are still in a relaxed mood as late as 1:03:50, joking about a bet on whether or not someone has just bought a fancy car, with A1 admonishing them not to talk about the wager and $\mathrm{A} 2$ and $\mathrm{A} 3$ grinning at him. And, conversely, they cannot see D1 return with D2 and D3 in tow. In a face-to-face setting, D1 might have used the joke as a transition point and a means of integrating the two sets of people, or the accountants might have abandoned the joke as he and the other developers entered. With neither side having access to information about the other side's readiness, however, the formal phase of the meeting begins abruptly. This exchange shows how setting up the technology, combined with the lack of visual and auditory cues, generates lumps and bumps in the alignment process that would not occur in face-to-face meetings.

While premeeting activities in face-to-face settings are generally a time of convergence, in this distributed setting the activities of the two sites remain disjointed. Traditional forms of note taking or audiotaping could have captured these actions independently, but it would have been difficult to "sync up" field notes across the two 
settings. ${ }^{8}$ For researchers, the confirmation of the tapes allows them to make statements about the activities, interactions, and reactions (or, often even more significant, lack thereof) on both sides of a link. With the tapes, we know with a high degree of certainty what each side heard across the link and how they incorporated that into their own local activities.

\subsection{Local Team Support for Discourse Across the Link}

Group cohesion and mutual support for team members are important parts of effective teamwork, particularly when subgroups come together for joint meetings. Without it, a spokesperson or decision maker for a subgroup cannot effectively represent them, especially in real-time problem solving situations. In face-to-face meetings, participants show support (or lack of support) for one another's positions through gesture, gaze, and body orientation. In the following excerpt, we see a marked difference in the nonverbal support subgroup members show each other. In the segment that follows, members of the accountants' team propose positions to which other members do not fully subscribe, while the designers, on their side, appear to be engaged in the co-construction of a response that involves all members (underlining indicates what the other side heard).

\begin{tabular}{|c|c|c|c|c|}
\hline & \multicolumn{2}{|c|}{ West Coast } & \multicolumn{2}{|c|}{ East Coast } \\
\hline ctr. & $\begin{array}{l}\text { accountants } \\
\text { nonverbal }\end{array}$ & $\begin{array}{l}\text { accountants } \\
\text { verbal }\end{array}$ & $\begin{array}{c}\text { developers } \\
\text { verbal }\end{array}$ & $\begin{array}{l}\text { developers } \\
\text { nonverbal }\end{array}$ \\
\hline 1:07:25 & $\begin{array}{l}\text { A3 glances down } \\
\text { briefly } \\
\text { A2 continues to look } \\
\text { at screen }\end{array}$ & $\begin{array}{l}\text { A2: Yeah. is there a } \\
\text { way to prioritize }\end{array}$ & & $\begin{array}{l}\text { D2 grimaces } \\
\text { D2 cocks his head, } \\
\text { looks off into space } \\
\text { and presses his lips } \\
\text { together } \\
\text { D1 leans his head } \\
\text { back }\end{array}$ \\
\hline 1:07:29 & $\begin{array}{l}\text { A2 turns toward the } \\
\text { speakerphone } \\
\text { A1 continues to look } \\
\text { at screen } \\
\text { A3 continues to look } \\
\text { at screen }\end{array}$ & $\begin{array}{l}\text { A2: when its } \\
\text { queued. similar to } \\
\text { the way [the main- } \\
\text { frame applicationl } \\
\text { works so that if you } \\
\text { had something that } \\
\text { you had to get } \\
\text { through that was. }\end{array}$ & & $\begin{array}{l}\text { D1 shakes his head } \\
\text { D2 turns halfway } \\
\text { between the phone } \\
\text { and D1 }\end{array}$ \\
\hline
\end{tabular}

${ }^{8}$ One would also need more sophisticated audiotaping equipment than the usual tape recorder, however, because it is almost impossible to clearly pick up what comes across a speakerphone. It is also easier to distinguish between multiple speakers and speakers with similar voices when audio is coupled with the visual cues of a videotape. 


\begin{tabular}{|c|c|c|c|c|}
\hline $1: 07: 35$ & $\begin{array}{l}\text { A2 turns back to the } \\
\text { screen }\end{array}$ & $\begin{array}{l}\text { A2: you know, a } \\
\text { higher priority than } \\
\text { say, five or eight } \\
\text { other jobs over } \\
\text { there, or since it runs } \\
\text { overnight. }\end{array}$ & & $\begin{array}{l}\text { D1 makes "hold off" } \\
\text { gesture - holds up } \\
\text { flat palm toward D2 } \\
\text { - and shakes his } \\
\text { head }\end{array}$ \\
\hline 1:07:39 & $\begin{array}{l}\text { A2 turns back to the } \\
\text { speakerphone }\end{array}$ & $\begin{array}{l}\text { A2: is that even an } \\
\text { issue? }\end{array}$ & & \\
\hline 1:07:40 & $\begin{array}{l}\text { A3 nods slightly } \\
\text { A2 nods slightly and } \\
\text { turns back to the } \\
\text { screen } \\
\text { A1 coughs }\end{array}$ & A2: Yeah & $\begin{array}{l}\text { D2: Not an issue } \\
\text { because it does one a } \\
\text { night and pretty } \\
\text { much everything } \\
\text { that's in there will } \\
\text { get executed. }\end{array}$ & $\begin{array}{l}\text { D2 turns back to- } \\
\text { ward the screen, } \\
\text { then looks some- } \\
\text { where between the } \\
\text { screen and the phone } \\
\text { D1 nods } \\
\text { D1 looks at hands }\end{array}$ \\
\hline 1:07:46 & $\begin{array}{l}\text { A2 nods, looks at } \\
\text { water bottle }\end{array}$ & A2: OK & & $\begin{array}{l}\text { D2 looks at phone } \\
\text { D1 looks at phone }\end{array}$ \\
\hline 1:07:49 & & & $\begin{array}{l}\text { D2: Does that an- } \\
\text { swer your question? }\end{array}$ & D2 looks at phone \\
\hline 1:07:50 & $\begin{array}{l}\text { A2 turns to speaker- } \\
\text { phone, then back to } \\
\text { screen }\end{array}$ & A2: Yes, thank you. & & \\
\hline 1:07:51 & $\begin{array}{l}\text { A } 2 \text { drinks from wa- } \\
\text { ter bottle }\end{array}$ & & $\begin{array}{l}\text { D2: OK, good. } \\
\text { Moving along, as D1 } \\
\text { introduced, the way } \\
\text { we wanted to set up } \\
\text { some wrappers } \\
\text { around the actual } \\
\text { requests themselves. }\end{array}$ & $\begin{array}{l}\text { D1 looks up, turns } \\
\text { toward screen } \\
\text { D1 nods, grabs ankle } \\
\text { again } \\
\text { D2 reaches for } \\
\text { mouse } \\
\text { D2 looks back and } \\
\text { forth }\end{array}$ \\
\hline 1:07:51 & & & $\begin{array}{l}\text { D2: we have imme- } \\
\text { diately coming up in } \\
\text { the view here in the } \\
\text { projects box and in } \\
\text { this example. }\end{array}$ & $\begin{array}{l}\text { D2 moves mouse } \\
\text { D1 plays with his } \\
\text { hands } \\
\text { D2 makes "offering" } \\
\text { gesture with hands } \\
\text { on "in this } \\
\text { example," keeping } \\
\text { hands close to his } \\
\text { lap }\end{array}$ \\
\hline 1:07:51 & $\begin{array}{l}\text { A3 flexes his neck, } \\
\text { glances briefly at his } \\
\text { notes }\end{array}$ & & $\begin{array}{l}\text { D2: this is not a } \\
\text { working program } \\
\text { yet. so there's really } \\
\text { no data behind it. } \\
\text { this is just some } \\
\text { hardcoded items } \\
\text { here. just for exam- } \\
\text { ple. for display pur- } \\
\text { poses. }\end{array}$ & $\begin{array}{l}\text { D2 makes brief "no, } \\
\text { no" gesture with his } \\
\text { hands still close to } \\
\text { his lap on "this is } \\
\text { not" }\end{array}$ \\
\hline
\end{tabular}


A2 begins to ask a question about how the application will relate to one aspect of their need for quick, ad hoc reports in response to questions from members of the executive team, "if you had something that you had to get through" (1:07:29). He ends his question, however, by admitting that it may be ill-founded ("is that even an issue?" 1:07:39). D2 answers, "Not an issue because it does one [run] a night." This is technically correct, but does not address the underlying problem: as currently set up, the application will not do the kind of on-demand reporting the accountants want. Why doesn't A2 then pursue his question? It is, after all, a legitimate issue, since it constitutes one of the key reasons for developing the application in the first place.

What is striking about this interaction when viewing the video tape is the difference in behavior on each side. When people speak in a group, they look to each other for support and encouragement. Neither the accountant who spoke, however, nor his two colleagues, look at each other during any part of this brief exchange. A1 and A3, in particular, continue to fixedly look at the screen during the entire interaction, with the exception of A3's brief downward glance at 1:07:25, leaving A2 without feedback from his team members. The developer's side, on the other hand, is far more active, with D2 grimacing at 1:07:25 as A2 starts to ask his question, an expression that is peripherally available to his boss, D1. He then looks at D1 (1:07:29) who shakes his head and appears to silently coach him on the answer (making a "hold off" gesture and shaking his head at 1:07:35). After obtaining verbal agreement from A2 that the issue has been addressed ("Does that answer your question?" 1:07:49 - "Yes, thank you," 1:07:50), D2 moves into the next section with D1 nodding his acknowledgment.

In this tape sequence, the video data alerted us to the fact that the lack of success of A2's question is foreshadowed in the failure of his team members to legitimize his question by a supportive focus of attention. Access to the videotapes enabled us to analyze how local group activity during cross-link question-answer sequences may display and legitimize differential authority and power. We might hypothesize from this sequence, for instance, that power is granted or withheld in real-time by the nonverbal actions of co-located team members, and that they signal support for further probing through body orientation, gesture and gaze. We might also hypothesize that these non-verbals help co-located group members maintain a sense of internal cohesion. For instance, later on in the videotape, D2 rolls his eyes at one of the accountants' suggestions and grins broadly at D1 and D3.

\subsection{Local Work and Global Work}

Gesture, gaze and body alignment, not available to the remote party, also accomplish silent "local work" in audio-only settings. We observed multiple instances in which people on one side of the link would signal to each other in various ways, showing each other notes, or even sketching out ideas and recommendations. This kind of local work allows each group to work through a problem and possible solutions. At the same time, it may prevent "global work" that is serious joint discussion around the potential solution space. Consider the following excerpt in which the accountants 
sketch out a private solution to a problem on their side of the link while the developers sketch out their own (underlining indicates what the other side heard; parentheses indicates something that seems to be an aside to the local group):

\begin{tabular}{|c|c|c|c|c|}
\hline & \multicolumn{2}{|c|}{ West Coast } & \multicolumn{2}{|c|}{ East Coast } \\
\hline ctr. & $\begin{array}{l}\text { accountants } \\
\text { nonverbal }\end{array}$ & $\begin{array}{l}\text { accountants } \\
\text { verbal }\end{array}$ & $\begin{array}{l}\text { developers } \\
\text { verbal }\end{array}$ & $\begin{array}{l}\text { developers } \\
\text { nonverbal }\end{array}$ \\
\hline $2: 02: 36$ & $\begin{array}{l}\text { A3 walks to screen, } \\
\text { starts pointing to } \\
\text { things on the screen } \\
\text { A3 lowers voice }\end{array}$ & $\begin{array}{l}\text { (A3: See, maybe } \\
\text { what we'd rather } \\
\text { have is this never } \\
\text { changes, that never } \\
\text { changes, then you } \\
\text { want to pull those to } \\
\text { the end, have these } \\
\text { so when you come } \\
\text { down you go straight } \\
\text { down, and you. } \\
\text { you're able to input } \\
\text { that and hit }\end{array}$ & & $\begin{array}{l}\text { D1 nods slightly, } \\
\text { looks at D3, who } \\
\text { looks back at D1 }\end{array}$ \\
\hline $2: 02: 48$ & $\begin{array}{l}\text { A3 makes tabbing } \\
\text { motions as he talks } \\
\text { about hitting the tab } \\
\text { key }\end{array}$ & $\begin{array}{l}\text { (A3: tab to go to the } \\
\text { next one. tab to go to } \\
\text { the next one and the } \\
\text { ones we don't use. } \\
\text { record type and these } \\
\text { two, put at the end } \\
\text { so. because you } \\
\text { rarely change those.) }\end{array}$ & & $\begin{array}{l}\text { D2 looks at D1, } \\
\text { makes a back and } \\
\text { forth gesture with } \\
\text { the pen in his hand }\end{array}$ \\
\hline 2:03:01 & A2 points to screen & $\begin{array}{l}\text { (A2: ...they rarely } \\
\text { change...they should } \\
\text { go in after...) }\end{array}$ & & $\begin{array}{l}\text { D2 mouths some- } \\
\text { thing to } D 1\end{array}$ \\
\hline 2:03:03 & & (A1: yeah, gotcha) & & \\
\hline \multicolumn{5}{|c|}{ [some discussion omitted] } \\
\hline $2: 04: 27$ & $\begin{array}{l}\text { A3 goes to white- } \\
\text { board }\end{array}$ & $\begin{array}{l}\text { A2: Those should be } \\
\text { the first items on } \\
\text { there }\end{array}$ & & \\
\hline 2:04:47 & $\begin{array}{l}\text { A3 starts listing } \\
\text { items on whiteboard }\end{array}$ & $\begin{array}{l}\text { (A3: CU, major. } \\
\text { detail) }\end{array}$ & & $\begin{array}{l}\text { D2 cocks his head } \\
\text { forward, "listening } \\
\text { pose"? }\end{array}$ \\
\hline 2:04:53 & & $\begin{array}{l}\text { (A1: and then the } \\
\text { other items) }\end{array}$ & $\begin{array}{l}\text { (D1: can you just } \\
\text { have it tab to corpor- } \\
\text { ate unit) }\end{array}$ & $\begin{array}{l}\text { D1 turns to D3, } \\
\text { draws something in } \\
\text { the air that looks like } \\
\text { a screen layout }\end{array}$ \\
\hline 2:04:54 & $\begin{array}{l}\text { A2 glances at the } \\
\text { screen, then back at } \\
\text { A3 }\end{array}$ & $\begin{array}{l}\text { (A3: Wouldn't you } \\
\text { want controlling en- } \\
\text { tity next?) }\end{array}$ & & $\begin{array}{l}\text { D1 makes downward } \\
\text { gesture }\end{array}$ \\
\hline
\end{tabular}




\begin{tabular}{|c|c|c|c|c|}
\hline 2:04:58 & & (A1: It doesn't...) & & \\
\hline 2:04:59 & & (A2: Yes) & $\begin{array}{l}\text { (D1: we can always } \\
\text { go back, wherever } \\
\text { the defaults go) }\end{array}$ & $\begin{array}{l}\text { D1 makes a "flip- } \\
\text { ping" gesture }\end{array}$ \\
\hline 2:05:00 & $\begin{array}{l}\text { A1 points to things } \\
\text { on the screen } \\
\text { A2 nods } \\
\text { A3 turns away from } \\
\text { the whiteboard }\end{array}$ & $\begin{array}{l}\text { (A1: Only for your } \\
\text { first piece of data, } \\
\text { fill in all this stuff, } \\
\text { the only thing you'll } \\
\text { be changing is these } \\
\text { three.) }\end{array}$ & & \\
\hline 2:05:06 & $\begin{array}{l}\text { A2 circles things on } \\
\text { the screen } \\
\text { A3 watches A2 }\end{array}$ & $\begin{array}{l}\text { (A2: You'll be } \\
\text { changing more fre- } \\
\text { quently than you'll } \\
\text { be changing these } \\
\text { things.) }\end{array}$ & & \\
\hline 2:05:10 & $\begin{array}{l}\text { A3 erases board } \\
\text { A1 turns to speaker- } \\
\text { phone }\end{array}$ & & $\begin{array}{l}\text { D2: Hey, guys, we } \\
\text { do have another idea } \\
\text { here that we can set } \\
\text { it up }\end{array}$ & $\begin{array}{l}\text { D1 gestures to D2 to } \\
\text { jump in }\end{array}$ \\
\hline 2:05:15 & $\begin{array}{l}\text { A1 turns back to } \\
\text { screen } \\
\text { A2 turns back to } \\
\text { screen }\end{array}$ & & $\begin{array}{l}\text { D2: where the tab } \\
\text { key will specifically } \\
\text { go to only those } \\
\text { items in a particular } \\
\text { order that you want } \\
\text { without even moving } \\
\text { anything. we can do } \\
\text { it that way alse. }\end{array}$ & \\
\hline $2: 05: 24$ & $\begin{array}{l}\text { A3 returns to stand } \\
\text { near his chair }\end{array}$ & & $\begin{array}{l}\text { D1: And then you } \\
\text { can use the mouse to } \\
\text { position yourself on } \\
\text { something else if you } \\
\text { wanted to }\end{array}$ & D1 looks at D3 \\
\hline
\end{tabular}

The developers have just demonstrated how accountants will select items for a report, but the accountants are not happy with the way in which the selections are laid out on the screen. At 2:02:36, A3 lowers his voice and begins a private discussion with the other accountants, with the developers able to overhear parts of the accountants' emerging design solution (the text with dotted underlining) even though they cannot see what $\mathrm{A} 3$ is pointing to on the screen at 2:02:36. The accountants continue laying out their own solution, with A3 suggesting, "the ones we don't use, record type and these two, put at the end so, because you rarely change those" (2:02:48); A2 echoing the solution, "they rarely change ... they should go in after" (2:03:01); and A1 agreeing, "yeah, gotcha" (2:03:03). 
After recognizing the problem (D1 nodding at 2:02:36), the developers begin to quietly sketch out their own solution, with D1 making eye contact with D3, then D2 starting to gesture with his pen (2:02:48) and mouthing something (2:03:01). This back-and-forth pattern continues without the accountants being aware of it. It may well be that they imagine the developers paying rapt attention to their emerging solution since they are producing their own talk in overhearable fashion. Instead, the developers are feeding off of this overhearable discussion to construct their own solution. At 2:04:47, the developers listen to the specific elements A3 lists ("CU, major, detail") that the accountants want as their first items on the screen layout. As the accountants continue overhearably, D1 quietly proposes an alternative to D3, "can you just have it tab to corporate unit?" (2:04:53), amplifying this and a further suggestion with gestures (2:04:53-2:04:52). Throughout this tape sequence, the developers speak softly enough that the accountants can't hear what they are saying. Their ability to overhear the accountants, however, allows them to jump in at a break in the action and propose the solution they have constructed ("Hey, guys, we do have another idea here" at 2:05:10). Their interruption closes off the accountants' construction of a solution and the accountants abandon the process. A3 erases the whiteboard he has been using (2:05:10) and returns to his chair (2:05:24), while A1 and A2 have already turned their attention to the screen (2:05:15).

This particular segment offers one example of how people move between local work and global work, and the role that overhearing can play. This kind of behavior can be recorded through conventional note taking, but not necessarily with sufficient detail about action, reaction, and timing on both sides to make comments about the role of local work, or form hypotheses about how such local work feeds into the global work of the group. The videotape helps us trace out the ways in which people move between the two types of work, and develop an understanding of the role which overhearing and the manipulation of voice can play in these settings.

The above examples illustrate some of the ways in which videotapes can supplement interviews and observations, becoming part of a larger data corpus from which insights can be drawn and through which hypotheses can be tested. They allow us access to certain kinds of information about an interaction, including the role of gesture, gaze, and body alignment, which are difficult to obtain by standard ethnographic methods. This is of particular benefit when dealing with interactions between remote sites where questions of alignment, of synching up, of shared understandings of openings and closings, topic changes, sequencing, and the like become paramount. Thus, video data help us ascertain how people move between informal and formal meeting segments in remote meetings, and how they move in and out of local work and global work when connected via an audio or audio-plus-video link. Other sequences we have analyzed helped us identify particular instances in which competing paradigms clashed, in which different understandings of the technologies led to an impasse, and in which the negative affordances of the technology led to breakdown. 


\section{ETHNOGRAPHY IN DISTRIBUTED WORK SETTINGS}

While there is widespread, popular belief that the new communication technologies will magically link people across distributed sites, the nature of the linkage is not well understood. We believe that many of the issues confronting designers and high-level decision makers regarding their development and use cannot be illuminated without the detailed, rigorous kind of analysis that video-based Interaction Analysis can provide. What is clear is that the positive and negative affordances of the new communication technologies are going to affect established work practices and work processes and eventually organizational structures. Laboratory studies are valuable for studying well defined variables in these domains, but the opportunities and barriers these technologies generate in the work place need to be explored by looking in a systematic manner at the ways in which real users doing real work in real work sites employ them. One promising way to capture and analyze these activities is through video-based Interaction Analysis.

\section{ACKNOWLEDGMENTS}

This research at THC was sponsored by Xerox Palo Alto Research Center, the Institute for Research on Learning, and THC. We wish to thank the members of the IA labs for their ideas, suggestions and commentaries. We also appreciate the comments of several anonymous reviewers, and the suggestions of Allen Lee, in shaping this article.

\section{REFERENCES}

Barley, S. R. (1988). “'On Technology, Time, and Social Order: Technically Induced Change in the Temporal Organization of Radiological Work." In A. Dubinskas (Editor), Making Time: Ethnographies of High-Technology Organizations. Philadelphia: Temple University Press, pp. 123-137.

Becker, H. S.; Geer, B.; Hughes, E.; and Strauss, A. (1977). Boys in White: Student Culture in Medical School. New Brunswick, New Jersey: Transaction Books.

Bentley, R.; Hughes, J.; Randall, D. Rodden, T.; Sawyer, P.; Shapiro, D.; and Sommerville, I. (1992). "Ethnographically-Informed System Design for AirTraffic Control." Proceedings of the Conference on Computer-Supported Cooperative Work. New York: ACM Press, pp. 123-129.

Beyer, H. R., and Holtzblatt, K. (1995). "Apprenticing with the Customer." Communications of the ACM, Volume 38, Number 5, pp. 45-52.

Bikson, T. K.; and Eveland, J. D. (1990). "The Interplay of Work Group Structures and Computer Support.” In. J. Galegher, R. E. Kraut, and C. Egido (Editors), 
Intellectual Teamwork: Social and Technological Foundations of Cooperative Work. Hillsdale, New Jersey: Lawrence Erlbaum Associates, pp. 245-290.

Blomberg, J.; Giacomi, J.; Mosher, A.; and Swenton-Wall, P. (1993). "Ethnographic Field Methods and Their Relation to Design." In D. Schuler and A. Namoika (Editors), Participatory Design: Perspectives on System Design. Hillsdale, New Jersey: Lawrence Erlbaum Associates, pp. 123-154.

Brown, J. S., and Duguid, P. (1991). “Organizational Learning and Communities-ofPractice: Toward a Unified View of Working, Learning, and Innovation." Organizational Science, Volume 2, Number 1, pp. 40-57.

Bucciarelli, L. L. (1994). Designing Engineers. Cambridge, Massachusetts: MIT Press.

Button, G. (Editor) (1993). Technology in Working Order: Studies of Work, Interaction and Technology. London: Routledge.

Daft, R. L., and Lengel, R. H. (1986). “Organizational Information Requirements, Media Richness and Structural Design.” Management Science, Volume 32, Number 5, pp. 554-571.

Darrah, C. (1992). "Workplace Skills in Context." Human Organization, Volume 51, Number 3, pp. 264-273.

Dourish, P., and Bellotti, V. (1992). "Awareness and Coordination in Shared Workspaces." New York: ACM Press.

Dubinskas, F. A. (Editor), (1988). Making Time: Ethnographies of High-Technology Organizations. Philadelphia: Temple University Press.

Ehn, P. (1988). Work-Oriented Design of Computer Artifacts. Hillside, New Jersey: Lawrence Erlbaum.

Ehrlich, K., and Cash, D. (1994). “Turning Information into Knowledge: Information Finding as a Collaborative Activity." Proceedings Digital Libraries '94. College Station, Texas. pp. 119-125.

Engeström, Y., and Middleton, D. (Editors) (1993). Communication and Cognition at Work. New York: Cambridge University Press.

Eveland, J. D.; Blanchard, A.; Brown, W.; and Mattocks, J. (1994). "The Role of 'Help Networks' in Facilitating Use of CSCW Technologies." In Proceedings of the 1994 Conference on Computer Supported Cooperative Work. Chapel Hill, North Carolina.

Garfinkel, H. (1984, c.1967). Studies in Ethnomethodology. Cambridge, England: Polity.

Gasser, L. (1986). "The Integration of Computing and Routine Work." ACM Transactions on Office Information Systems, Volume 4, Number 3, pp. 205-225.

Gaver, W. W. (1992). The Affordances of Media Spaces for Collaboration. New York: ACM Press.

Gerson, E., and Star, S. L. (1986). "Analyzing Due Process in the Workplace." ACM Transactions on Office Information Systems, Volume 4, Number 3, pp. 257-270.

Gladwell, M. (1996). "The Science of Shopping." The New Yorker, November 4, pp. 66-75. 
Glaser, B., and Strauss, A. (1967). The Discovery of Grounded Theory: Strategies for Qualitative Research. Hawthorne, New York: Aldine de Gruyter.

Greenbaum, J., and Kyng, M. (Editors) (1991). Design at Work: Cooperative Design of Computer Systems. Hillsdale, New Jersey: Lawrence Erlbaum Associates.

Gregory, K. L. (1983). "Native-View Paradigms: Multiple Cultures and Culture Conflicts in Organizations." Administrative Sciences Quarterly, Volume 28, pp. 359-376.

Grudin, J. (1994). “Groupware and Social Dynamics: Eight Challenges for Developers." Communications of the ACM, Volume 37, Number 1, pp. 92-105.

Heath, C., and Luff, P. (Editors) (1991). "Collaborative Activity and Technological Design: Task Coordination in London Underground Control Rooms." Proceedings of the Second European Conference on Computer-Supported Cooperative Work. Amsterdam, The Netherlands.

Heath, C., and Luff, P. (1993). "Disembodied Conduct: Interactional Asymmetries in Video-Mediated Communication." Technology in Working Order: Studies of Work, Interaction, and Technology. London: Routledge, pp. 35-54.

Hiltz, S. R., and Turoff, M. (1993). The Network Nation: Human Communication via Computer, Revised Edition. Cambridge, Massachusetts: MIT Press.

Holtzblatt, K., and Beyer, H. (1993). "Making Customer-Centered Design Work for Teams." Communications of the ACM, Volume 36, Number 10, pp. 93-103.

Hughes, J.; Randall, D.; and Shapiro, D. (1993). "From Ethnographic Record to System Design." Journal of Computer Supported Cooperative Work, Volume 1, Number 3, pp. 123-141.

Jordan, B. (1992). Technology and Social Interaction: Notes on the Achievement of Authoritative Knowledge in Complex Settings. Palo Alto, California: Institute for Research on Learning.

Jordan, B. (1993, c. 1983). Birth in Four Cultures: A Crosscultural Investigation of Childbirth in Yucatan, Holland, Sweden, and the United States, Fourth Exanded Edition, revised by R. Davis-Floyd. Prospect Heights, Illinois: Waveland Press, Inc.

Jordan, B. (1996a). “Ethnographic Workplace Studies and CSCW.” In D. Shapiro, M. Tauber and R. Traunmüller (Editors), The Design of Computer Supported Cooperative Work and Groupware Systems. Amsterdam: North Holland, pp. 1742.

Jordan, B. (1996b). “Transforming Ethnography - Reinventing Research.” In J. Schiestl and H. Schelle (Editors), Groupware - Software für die Teamarbeit der Zukunft: Grundlegende Konzepte und Fallstudien. Marburg, Germany: Tectum Verlag, pp. 200-212.

Jordan, B., and Henderson, A. (1995). "Interaction Analysis: Foundations and Practice." The Journal of the Learning Sciences, Volume 4, Number 1, pp. 39-103.

Korpela, E. (1994). "Path to Notes: A Networked Company Choosing its Information Systems Solution.” In R. Baskerville, S. Smithson, O. Ngwenyama, and J. I. 
DeGross, Transforming Organizations with Information Technology. Amsterdam: North-Holland.

Lave, J., and Wenger, E. (1991). Situated Learning: Legitimate Peripheral Participation. Cambridge, England: Cambridge University Press.

Lee, A. S. (1994). "Electronic Mail as a Medium for Rich Communication: An Empirical Investigation Using Hermeneutic Interpretation." MIS Quarterly, Volume 18, Number 2, pp. 143-157.

Lofland, J. (1995). Analyzing Social Settings: A Guide to Qualitative Observation and Analysis, Third Edition. Belmont, California: Wadsworth.

Malinowski, B. (1922). Argonauts of the Western Pacific. New York: E. P. Dutton, Inc.

Malinowski, B. (1979, c. 1927). Sex and Repression in Savage Society. London: Routledge and Kegan Paul.

Markus, M. L. (1994). "Finding a Happy Medium: Explaining the Negative Effects of Electronic Communication on Social Life at Work." ACM Transactions on Information Systems, Volume 12, Number 2, pp. 119-149.

Markus, M. L., and Bjørn-Andersen, N. (1987). "Power Over Users: Its Exercise by System Professionals." Communications of the ACM, Volume 30, Number 6.

Mead, M. (1930). Growing up in New Guinea. New York: Mentor Book.

Mead, M. (1973, c. 1928). Coming of Age in Samoa. New York: American Museum of Natural History.

Nardi, B. A.; Kuchinsky, A.; Whittaker, S.; Leichner, R.; and Schwarz, H. (1995). "Video-as-Data: Technical and Social Aspects of a Collaborative Multimedia Application." International Journal of Computer Supported Cooperative Work, Volume 4, Number 1, pp. 73-100.

Naroll, R., and Cohen, R. (1973). A Handbook of Method in Cultural Anthropology. New York: Columbia University Press.

Orlikowski, W. J. (1993). "Learning from NOTES: Organizational Issues in Groupware Implementation." The Information Society, Volume 9, pp. 237-250.

Orlikowski, W. J., and Gash, D. C. (1994). "Technological Frames: Making Sense of Information Technology in Organizations." ACM Transactions on Information Systems, Volume 12, Number 2, pp. 174-207.

Orr, J. (1996). Talking About Machines: An Ethnography of the Modern Job. Ithaca, New York: ILR Press.

Roschelle, J., and Goldman, S. (1991). "VideoNoter: A Productivity Tool for Video Data Analysis." Behavior Research Methods, Instruments, and Computers, Volume 23, Number 2, p. 219.

Ruhleder, K. (1994). "Rich and Lean Representations of Information for Knowledge Work: The Role of Computing Packages in the Work of Classical Scholars." Transactions on Office Information Systems, Volume 12, Number 2, pp. 208-230. Ruhleder, K. (1995). "Reconstructing Artifacts, Reconstructing Work: From Textual Edition to On-Line Databank." Science, Technology and Human Values, Volume 29, Number 1, pp. 39-64. 
Ruhleder, K.; Jordan, B.; and Elmes, M. (1996). "Wiring the 'New Organization': Integrating Collaborative Technologies and Team-Based Work." 1996 Academy of Management, OCIS Division. [URL: http://alexia.lis.uiuc.edu/ ruhleder/ publications/96.academy.html]

Sanderson, P.; Scott, J.; Johnston, T.; and Mainzer, J. (1994). MacSHAPA and the Enterprise of Exploratory Sequential Data Analysis (ESDA). International Journal of Human-Computer Studies, Volume 41, Number 5, p. 633.

Shapiro, D.; Tauber, M.; and Traunmüller, R. (Editors) (1996). The Design of Computer-Supported Cooperative Work and Groupware Systems. Amsterdam: North Holland.

Sproull, L., and Kiesler, S. (1991). Connections: New Ways of Working in the Networked Organization. Cambridge, Massachusetts: MIT Press.

Star, S. L. (Editor) (1995). The Cultures of Computing. Cambridge, Massachusetts: Blackwell Publishers.

Star, S. L., and Ruhleder, K. (1996). "Steps Towards and Ecology of Infrastructure: Design and Access for Large Information Spaces." Information Systems Research, Volume 7, Number 1, pp. 111-134.

Strauss, A. (1986). Qualitative Methods for Social Scientists. Cambridge, England: Cambridge University Press.

Suchman, L. (1987). Plans and Situated Actions: The Problem of Human-Machine Communication. Cambridge, England: Cambridge University Press.

Suchman, L., and Trigg, R. (1991). "Understanding Practice: Video as Medium for Reflection and Design." In J. Greenbaum and M. Kyng (Editors), Design at Work: Approaches to Collaborative Design. Hillsdale, New Jersey: Lawrence Erlbaum Associates.

Van Maanen, J. (1988). Tales of the Field. Chicago: University of Chicago Press. Wolcott, H. F. (1973). The Man in the Principal's Office: An Ethnography. New York: Holt, Rinehart and Winston.

Yates, J., and Van Maanen, J. (1996). "Editorial Notes for the Special Issue." Information Systems Research, Volume 7, Number 1, pp. 1-4.

\section{BIOGRAPHY}

Karen Ruhleder works in the interdisciplinary area of social informatics. Her research and teaching crosses the areas of information technology, the ethnography of information systems, and organizational theory. Her past work has included evaluations of the integration of scholarly workstations into humanistic and scientific disciplines. Current research projects focus on the impact of information and communication technologies on work practices and organizational design, especially the emergence of socio-technical infrastructures to support geographically-distributed collaborative work. She is particularly interested in the integration of information and 
communication technologies into distributed workgroups, and the emergence of virtual learning communities. The venues for her work have included both academic and corporate settings.

Brigitte Jordan is an anthropologist with interests in the participatory design of productive and supportive work settings. She has done research in industrial and pre-industrial communities in the US, Europe, and several developing countries, tracing the influence of social and technological innovations on work practice, quality of life, and organizational change. Her long-range research interests revolve around the changing nature of work and leisure under the impact of the new communication and information technologies and the consequent transformation of ways of life, societal institutions, and global economies. Current projects focus on understanding and improving complex work settings in the production and service sectors, the support of organizational learning, and tool building to support knowledge management and work redesign. 